\title{
Uso de fungos micorrízicos arbusculares (FMA) na promoção do crescimento de mudas de pinheira (Annona squamosa L., Annonaceae) ${ }^{1}$
}

\author{
Ieda Ribeiro Coelho², Uided Maaze Tibúrcio Cavalcante ${ }^{3}$, \\ Maryluce Albuquerque da Silva Campos e Fabio Sergio Barbosa da Silva ${ }^{2,4,5}$
}

Recebido em 7/10/2011. Aceito em 20/07/2012

\begin{abstract}
RESUMO
(Uso de fungos micorrízicos arbusculares (FMA) na promoção do crescimento de mudas de pinheira (Annona squamosa L. Annonaceae). Os fungos micorrízicos arbusculares (FMA) podem ser usados na formação de mudas frutíferas, porém o seu efeito na pinheira não é conhecido. Foi investigado o papel de dois isolados de FMA (Acaulospora longula e Gigaspora albida) na promoção do crescimento de mudas de pinheira. O delineamento experimental foi tipo inteiramente casualizado em seis tratamentos: 1) Controle não inoculado em solo; 2) Controle não inoculado em solo adubado; 3) Inoculado com A. longula em solo; 4) Inoculado com A. longula em solo adubado; 5) Inoculado com G. albida em solo; 6) Inoculado com G. albida em solo adubado, em quatro repetições, totalizando 24 unidades. Plântulas com duas folhas foram inoculadas na região das raízes com solo-inóculo fornecendo 200 esporos de $G$. albida ou de A. longula. Após 140 dias em casa de vegetação avaliou-se: altura, número de folhas, diâmetro do caule, área foliar, massa fresca e seca da parte aérea e radicular, colonização micorrízica e produção de esporos de FMA. Em solo não adubado, os benefícios da micorrização foram evidenciados nas mudas formando simbiose com G. albida. Em solo com vermicomposto, a micorrização não incrementou o crescimento da mudas. A micorrização com $G$. albida pode ser alternativa para produção de mudas de pinheira, dispensando a fertilização.
\end{abstract}

Palavras-chave: Annonaceae, Glomeromycota, adubação orgânica

\begin{abstract}
(Use of arbuscular mycorrhizal fungi (AMF) to promote the growth of sugar apple seedlings (Annona squamosa $\mathrm{L}$. Annonaceae)). Arbuscular mycorrhizal fungi (AMF) can be used to promote seedling growth of fruit trees, but their effect on sugar apple is not known. We investigated the role of two isolates of AMF (Acaulospora longula and Gigaspora albida) in promoting the growth of sugar apple seedlings. The experimental design was completely randomized with six treatments and four replicates (totaling 24 units): 1) uninoculated control; 2) uninoculated control in fertilized soil; 3) inoculated with A. longula in soil, 4) inoculated with A. longula in fertilized soil, 5) inoculated with G. albida in soil; 6) inoculated with G. albida in fertilized soil. Seedlings with two leaves were inoculated in the region of the roots with soil-inocula with 200 spores of G. albida or A. longula. After 140 days in a greenhouse the height, leaf number, stem diameter, leaf area, fresh and dry weight of shoot and root, root colonization and production of spores were evaluated. The seedlings benefited from G. albida mycorrhiza when grown in unfertilized soil. Mycorrhizal inoculation did not increase the growth of seedlings in soil with vermicompost. The use G. albida is an alternative in the production of sugar apple seedlings, instead of fertilizers.
\end{abstract}

Key words: Annonaceae, Glomeromycota, organic amendment

\footnotetext{
${ }^{1}$ Parte da monografia do primeiro Autor

${ }^{2}$ Universidade de Pernambuco, Laboratório de Enzimologia e Fitoquímica Aplicada à Micologia, Petrolina, PE, Brasil

${ }^{3}$ Universidade Federal de Pernambuco, Departamento de Micologia, Laboratório de Micorrizas, Petrolina, PE, Brasil

${ }^{4}$ Universidade de Pernambuco, Programa de Pós-Graduação em Biologia Celular e Molecular Aplicada, Instituto de Ciências Biológicas, Petrolina, PE, Brasil

${ }^{5}$ Autor para correspondência: fabio.barbosa@pesquisador.cnpq.br
} 


\section{Introdução}

A pinheira pertence à família Annonaceae, cuja distribuição ocorre em várias regiões do mundo, contudo o Brasil e a Índia se destacam como as regiões com maior área plantada. Nesse sentido, a região Nordeste do Brasil propicia excelentes condições para o cultivo da pinha e esta cultura ocupa espaço importante no agronegócio frutícola (Araújo 2003). A produção da pinha destina-se ao mercado interno nos grandes centros consumidores da fruta (Araújo et al. 2008).

Os fungos micorrízicos arbusculares (FMA) formam associação mutualista com a maioria de plantas vasculares, onde a planta fornece substrato energético ao fungo, e este, pelo micélio externo, capta nutrientes do solo e os transfere à planta hospedeira, proporcionando maior crescimento ao vegetal (Genre \& Bonfante 2010). Tal associação é conhecida como micorriza. Esta simbiose também confere à planta maior tolerância a estresses ambientais de natureza biótica e abiótica (Moreira \& Siqueira 2002), como ocorre no transplantio de mudas para o campo (Vandresen et al. 2007).

Devido ao melhor estado nutricional da planta associada, diversas pesquisas têm demonstrado que a aplicação de FMA na fase de muda favorece o crescimento vegetal, reduzindo o tempo de viveiro (Silveira \& Gomes 2007).

$\mathrm{O}$ aumento no interesse pelo cultivo orgânico de fruteiras justifica-se devido ao anseio mundial por frutos oriundos de modelos agrícolas mais sustentáveis; pesquisas têm sido feitas para avaliar os efeitos da aplicação de composto orgânico no crescimento, desenvolvimento e produção de fruteiras (Domatto Junior et al. 2007; Souza et al. 2003). Outro aspecto que deve ser considerado no agronegócio sustentável está associado ao benefício dos adubos orgânicos no estabelecimento da associação micorrízica arbuscular (Caravaca et al. 2004; Cavander et al. 2003; Martin et al. 2002). Nesse aspecto, o meio de cultivo deve ser ajustado para permitir a máxima resposta da simbiose micorrízica (Borges et al. 2003).

Os FMA têm potencial para uso biotecnológico na produção de mudas de algumas espécies arbóreas utilizadas em programas de revegetação (Pouyu-rojas et al. 2006; Caldeira et al. 1997), em plantas ornamentais (Silva et al. 2006), em culturas de interesse econômico (Martin et al. 2002) e em fruteiras como: gravioleira (Silva et al. 2008; Chu et al. 2001), abacateiro (Silveira et al. 2002), bananeira (Trindade et al.
2003; Yano-Melo et al.,1999), aceroleira (Costa et al. 2001), mangabeira (Costa et al. 2005), mamoeiro (Trindade et al. 2001), goiabeira (Schiavo \& Martins 2002), maracujazeiro-doce (Silva et al. 2004) e maracujazeiro-amarelo (Soares et al. 2003; Cavalcante et al. 2002), entre outras, por maximizar o crescimento e/ou a produtividade.

Apesar dos benefícios comprovados em outras anonáceas (Silva et al. 2008; Chu et al. 2001) não está esclarecido o papel dos FMA na promoção do crescimento de pinheiras. Portanto, o presente trabalho visa selecionar a combinação de FMA + tipo de substrato ideal para produção de mudas de pinheira. Testou-se a hipótese de que a micorrização maximiza o crescimento de mudas de pinheira, com o substrato e a fonte de inóculo micorrízico interferindo nas respostas obtidas.

\section{Material e métodos}

O experimento foi conduzido em casa de vegetação, na Universidade Estadual da Bahia (UNEB), em Juazeiro - BA. O delineamento experimental foi do tipo inteiramente casualizado em seis tratamentos: 1) Controle não inoculado em solo; 2) Controle não inoculado em solo adubado; 3 ) Inoculado com Acaulospora longula em solo; 4) Inoculado com Acaulospora longula em solo adubado; 5) Inoculado com Gigaspora albida em solo; 6) Inoculado com Gigaspora albida em solo adubado, em quatro repetições, totalizando 24 unidades experimentais.

Foram testados dois tipos de substratos: solo e solo $+10 \%$ de vermicomposto. O solo foi coletado em área de Caatinga nativa, próximo ao $\mathrm{Km} \mathrm{152,} \mathrm{no} \mathrm{município} \mathrm{de} \mathrm{Petrolina-PE}$ e esterilizado com Bromex ( $98 \%$ de brometo de metila e 2 $\%$ de cloropicrina), que na instalação do experimento ainda era comercializado. Após esterilização tanto o solo quanto o solo + vermicomposto foram encaminhados para análise química na Embrapa Semi-Árido (Tab. 1).

Sementes de pinheira, comercializadas na Cohab Massangano, Petrolina-PE, foram colocadas para germinar em bandejas contendo solo desinfestado com Bromex e quando tinham duas folhas definitivas foram transferidas para o respectivo substrato (com ou sem adubo) e inoculadas, na região das raízes, com solo-inóculo fornecendo 200 esporos de Acaulospora longula Spain \& N.C. Schenck (UFPE 21) ou Gigaspora albida N.C. Schenck \& G.S. Sm (UFPE 01). Parte

Tabela 1. Caracterização química dos substratos usados para cultivo de mudas de pinheira

\begin{tabular}{llc}
\hline Características & \multicolumn{2}{c}{ Substratos } \\
\hline & Solo & Solo + 10 \% de vermicomposto \\
$\mathrm{MO}(\mathrm{g} / \mathrm{Kg})$ & 3,41 & 7,55 \\
$\mathrm{P}\left(\mathrm{mg} / \mathrm{dm}^{3}\right)$ & 4,00 & 20,00 \\
$\mathrm{pH}\left(\mathrm{H}_{2} \mathrm{O}-1: 2,5\right)$ & 4,90 & 5,80 \\
$\mathrm{CTC}\left(\mathrm{cmol} / \mathrm{dm}^{3}\right)$ & 5,18 & 5,72 \\
\hline
\end{tabular}

$\mathrm{MO}=$ matéria orgânica; $\mathrm{CTC}=$ capacidade de troca de cátions. 
das plântulas permaneceu sem inoculação, constituindo o tratamento controle. Os inóculos de FMA utilizados foram produzidos em solo, tendo como hospedeiro o painço $(\mathrm{Pa}$ nicum miliaceum L.), no Departamento de Micologia da Universidade Federal de Pernambuco (UFPE).

Após 140 dias da inoculação foram avaliados: diâmetro do caule a $2,5 \mathrm{~cm}$ do solo, altura da plantas, número de folhas, área foliar, massa fresca e seca da parte aérea, massa fresca e seca da parte subterrânea, densidade de esporos e colonização micorrízica. A matéria seca foi determinada após a secagem do material em estufa com circulação de ar $\left(40^{\circ} \mathrm{C}\right)$ até peso constante. Os esporos foram quantificados em estereomicroscópio $(40 \mathrm{x}$ ) após extração dos glomerosporos pelas técnicas da decantação e peneiramento em via úmida (Gerdemann \& Nicolson 1963; Jenkins 1964). A colonização micorrízica foi determinada pela técnica da interseção de quadrantes (Giovannetti \& Mosse 1980) após diafanização das raízes com $\mathrm{KOH} 10 \%, \mathrm{H}_{2} \mathrm{O}_{2} 1 \%$ e coloração com Clorazol Black-E (Brundrett et al. 1984).

Os dados de colonização micorrízica foram transformados em $\sqrt{ } x+0,5$ para atingir a homogeneidade de variância, submetidos à ANOVA e as médias comparadas pelo teste de Tukey (5\%), utilizando o programa Statistica (Statsoft 2002).

\section{Resultados e discussão}

Houve efeito dos tratamentos de adubação e de FMA sobre as variáveis estudadas $(\mathrm{P}<0,05)$. A inoculação com FMA favoreceu o crescimento de mudas de pinheira, mas os benefícios dependeram da composição do substrato de cultivo (Tab. 2).

Em solo não adubado, com exceção da altura, os maiores benefícios da micorrização foram evidenciados nas mudas em simbiose com G. albida. Por outro lado, a inoculação com $A$. longula não trouxe benefícios diferenciados do controle sem o fungo, para a maioria dos parâmetros avaliados (Tabela 2). Resposta inversa foi encontrada em mudas de Annona muricata L. var. 'Morada' (Silva et al. 2008). Assim, comprova-se que o comportamento vegetal quanto à mi- corrização é diferenciado entre plantas do mesmo gênero (Pouyu-rojas et al. 2006). Geralmente, observam-se maiores incrementos no crescimento do vegetal hospedeiro decorrente da micorrização em solos com baixa disponibilidade de nutrientes (Silva et al. 2008; Chu et al. 2001). Tal comportamento foi observado neste trabalho, pois o substrato sem adubo, que apresentava menos fósforo em comparação ao tratamento ao solo adubado (Tab. 1), propiciou melhor atuação dos FMA, com especial destaque para G. albida.

Observou-se também que mudas cultivadas em solo sem adubo e associadas a G. albida produziram mais raízes em relação aos demais tratamentos em solo sem adubo, mas sem diferir dos tratamentos adubados (Tab. 2). Na formação de mudas, o sistema radicular desenvolvido pode melhorar as condições de estabelecimento em campo (Bernardi et al. 2000). O menor crescimento da parte área e maior investimento nas raízes ocorrem geralmente quando a disponibilidade de minerais no solo é baixa (Hodge 2004). No entanto, a planta só poderá investir nas raízes se houver absorção de fósforo suficiente para alocação do carbono visando a produção dos tecidos radiculares (Bernardi et al. 2000). Desse modo, a micorrização utilizando de G. albida incrementou a biomassa das raízes.

A inoculação com G. albida favoreceu o crescimento de mudas de pinheira e resultados semelhantes foram obtidos em outras culturas usando o mesmo isolado de FMA, como maracujazeiro-amarelo (Cavalcante et al. 2002), maracujazeiro-doce (Silva et al. 2004) e mangabeira (Costa et al. 2005).

A aplicação conjunta de substratos orgânicos e FMA pode resultar em efeito sinérgico positivo no crescimento vegetal (Silva et al. 2008). Tal comportamento não foi registrado no presente trabalho (Tab. 2). Materiais orgânicos quando devidamente aplicados podem otimizar os efeitos da simbiose micorrízica arbuscular (Caravaca et al. 2004), comportamento. não registrado no presente estudo, considerando que os benefícios da micorrização foram mitigados em solo adubados; provavelmente, o nível de fósforo no solo adubado, que estava em torno de $20 \mathrm{mg} \cdot \mathrm{dm}^{-3}$, inibiu

Tabela 2. Altura (ALT), no de folhas (NF), diâmetro do caule (DC), área foliar (AF), massa fresca e seca da parte aérea e subterrânea de mudas de pinheira associadas ou não a fungos micorrízicos arbusculares (FMA) e cultivadas em solo com ou sem vermicomposto (V), 140 dias após a inoculação, em casa de vegetação

\begin{tabular}{|c|c|c|c|c|c|c|c|c|}
\hline \multirow[t]{2}{*}{ Trat. } & \multicolumn{8}{|c|}{ Variáveis } \\
\hline & $\operatorname{ALT}(\mathrm{cm})$ & $\mathrm{NF}$ & $\mathrm{DC}(\mathrm{cm})$ & $\mathrm{AF}\left(\mathrm{cm}^{2}\right)$ & MFPA (g) & MSPA (g) & MFPS (g) & MSPS (g) \\
\hline $\mathrm{C}$ & $18,75 \mathrm{~d}$ & $7,00 \mathrm{~d}$ & $2,92 \mathrm{c}$ & $17,78 \mathrm{~d}$ & $1,76 \mathrm{c}$ & $0,44 \mathrm{c}$ & $3,10 \mathrm{~b}$ & $0,26 b$ \\
\hline $\mathrm{Al}$ & $24,50 \mathrm{c}$ & $12,00 \mathrm{c}$ & $3,52 \mathrm{c}$ & $43,81 d$ & $3,69 c$ & $0,98 \mathrm{c}$ & $4,22 \mathrm{~b}$ & $0,38 \mathrm{~b}$ \\
\hline $\mathrm{Ga}$ & $29,25 c$ & $18,00 \mathrm{~b}$ & $4,58 \mathrm{~b}$ & $118,39 \mathrm{c}$ & $8,52 b$ & $2,61 b$ & $11,61 \mathrm{a}$ & $1,92 \mathrm{a}$ \\
\hline $\mathrm{C}+\mathrm{V}$ & $44,25 a$ & $22,00 \mathrm{a}$ & $5,82 \mathrm{a}$ & $187,71 a$ & $15,87 \mathrm{a}$ & $5,16 a$ & $15,62 \mathrm{a}$ & $2,49 a$ \\
\hline$A l+\mathrm{V}$ & $37,25 b$ & $21,75 \mathrm{a}$ & $5,85 a$ & $174,54 \mathrm{~b}$ & $13,69 b$ & $4,72 \mathrm{a}$ & $15,71 \mathrm{a}$ & $2,46 a$ \\
\hline$G a+V$ & $38,75 b$ & $22,75 a$ & $6,12 \mathrm{a}$ & $182,25 \mathrm{ab}$ & $15,36 \mathrm{a}$ & $5,27 \mathrm{a}$ & $17,71 \mathrm{a}$ & $2,08 \mathrm{a}$ \\
\hline
\end{tabular}

$\mathrm{C}=$ Controle; $\mathrm{Al}=$ Acaulospora longula $\mathrm{Ga}=$ Gigaspora albida $\mathrm{MFPA}=$ massa fresca da parte aérea; MSPA= massa seca da parte aérea; MFPS= massa fresca da parte subterrânea; MSPS= massa seca da parte subterrânea.

Médias seguidas da mesma letra, nas colunas, não diferem pelo teste de Tukey (5\%). 
Tabela 3. Colonização micorrízica e produção de esporos de fungos micorrízicos arbusculares (FMA) na rizosfera de mudas de pinheira associadas a FMA, após 140 dias da inoculação, em casa de vegetação.

\begin{tabular}{lcc}
\hline Tratamentos & Colonização micorrízica (\%) & ${\text { No de esporos }\left(25 \mathrm{~g}^{-1} \text { solo }\right)}^{0,00 \mathrm{~b}}$ \\
\hline Controle & $0,00 \mathrm{~b}$ & $14,00 \mathrm{ab}$ \\
Acaulospora longula & $32,40 \mathrm{a}$ & $34,25 \mathrm{a}$ \\
Gigaspora albida & $35,23 \mathrm{a}$ & $0,00 \mathrm{~b}$ \\
Controle + V & $0,00 \mathrm{~b}$ & $34,00 \mathrm{ab}$ \\
A. longula + V & $38,59 \mathrm{a}$ & $51,75 \mathrm{a}$ \\
G. albida + V & $59,47 \mathrm{a}$ & \\
\hline
\end{tabular}

$\mathrm{V}=$ vermicomposto; Médias seguidas da mesma letra, nas colunas, não diferem pelo teste de Tukey (5\%).

a atuação dos FMA, conforme sugerido por Moreira \& Siqueira (2002).

A presença de adubo no substrato não afetou a colonização radicular e a esporulação dos dois FMA estudados (Tab. 3). França et al. (2007) também observaram que a adubação orgânica não interferiu na colonização em raízes de citrus. Vários fatores podem ter contribuído para tal resposta, como a quantidade de fósforo no substrato (Cavalcante et al. 2002), as características genéticas da planta (Costa et al. 2001) e dos isolados de FMA utilizados (Silva et al. 2008).

Houve correlação positiva entre colonização micorrízica e densidade de esporos. Segundo Silveira (1998) os fatores que geralmente estimulam ou inibem a colonização também alteram a esporulação dos fungos. $\mathrm{O}$ uso de resíduos orgânicos pode favorecer o estabelecimento de FMA com estímulo da esporulação (Douds et al. 2006; Gryndler et al. 2003), da colonização (Silva et al. 2008) ou não interferir (Gryndler et al. 2008) nesses processos, considerando que isolados de FMA respondem de maneira diferenciada à composição dos substratos (Vaidya et al. 2007).

Apesar dos FMAs não possuírem especificidade hospedeira, estudos indicam a existência de certa compatibilidade funcional entre os simbiontes (Pouyu-Rojas et al. 2006), no entanto, a composição do substrato modula as respostas obtidas. Isso foi observado neste trabalho, considerando que maiores incrementos foram alcançados pela associação com G. albida em solo não adubado. Desse modo a inoculação micorrízica pode ser uma alternativa para a produção de mudas de pinheira, sem a utilização de adubos. Os resultados indicam que o produtor pode optar pelo uso de FMA para produção de mudas de pinheira em solo não adubado, cujos benefícios são similares aos obtidos em solo adubado sem FMA. Entretanto, a micorrização na fase de muda pode garantir aumento na produtividade em campo (Ilbas \& Sahin 2005). Ensaios futuros devem validar os benefícios da micorrização de mudas de pinheira com G. albida em condições de campo.

\section{Agradecimentos}

Ao $\mathrm{CNPq}$, Conselho Nacional de Desenvolvimento Científico e Tecnológico, pelo apoio financeiro.

\section{Referencias bibliográficas}

Araújo, J.F. 2003. A Cultura da Pinha. Salvador, Universidade do Estado da Bahia. Egba, Salvador.

Araújo, J.F;; Leonel, S. \& Pereira Neto, J. 2008. Adubação organomineral e biofertilização líquida na produção de frutos de pinheira (Annona squamosa L.) no submédio São Francisco, Brasil. Bioscience Journal 24: 48-57.

Bernardi, A.C.C.; Carmello, Q.A.C. \& Carvalho, S.A. 2000. Desenvolvimento de mudas de citros cultivadas em vaso em resposta à adubação NPK. Scientia Agricola 57: 733-738.

Borges, A.L.; Trindade, A.V.; Souza, L.S. \& Silva, M.N.B. 2003. Cultivo orgânico de fruteiras Tropicais - Manejo do solo e da cultura. Cruz das almas, EMBRAPA - CNPMF.

Brundrett, M.C.; Piché, Y. \& Peterson, R.L. 1984. A new method for observing the morphology of vesicular-arbuscular mycorrhizae. Canadian Journal of Botany 62: 2128-2134.

Caldeira, M.V.W.; Silva, E.M.R.; Franco, A.A. \& Zanon, M.L.B. 1997. Crescimento de leguminosas arbóreas em respostas à inoculação com fungos micorrízicos arbusculares. Ciência Florestal 7: 1-10.

Caravaca, F.; Alguacil, M.M.; Azcón, R.; Díaz, G. \& Roldán, A. 2004. Comparing the effectiveness of mycorrhizal inoculation and amendment with sugar beet, rock phosphate and Aspergillus niger to enhance field performance of the leguminous shrub Dorycnium pentaphyllum L. Applied Soil Ecology 25: 169-180.

Cavalcante, U.M.T.; Maia, L.C.; Costa, C.M.C.; Cavalcante, T. \& Santos, V.F. 2002. Efeito de fungos micorrízicos arbusculares, da adubação fosfatada e da esterilização do solo no crescimento de mudas de maracujazeiro amarelo. Revista Brasileira de Ciência do Solo 26: 1099-1106.

Cavender, N.D.; Atiyeh, R.H. \& Knee, M. 2003. Vermicompost stimulates mycorrhizal colonization of roots of Sorghum bicolor at the expense of plant growth. Pedobiologia 47: 85-89.

Chu, E.Y.; Möller, M.R.F. \& Carvalho, J.G. 2001. Efeito da inoculação micorrízica em mudas de gravioleira em solo fumigado e não fumigado. Pesquisa Agropecuária Brasileira 36: 671-680.

Costa, C.M.C.; Cavalcante, U.M.T.; Goto, B.T.; Santos, V.F. \& Maia, L.C. 2005. Fungos micorrízicos arbusculares e adubação fosfatada em mudas de mangabeira. Pesquisa Agropecuária Brasileira 40: 225-232.

Costa, C.M.C.; Maia, L.C.; Cavalcante, U.M.T. \& Nogueira, R.J.M.C. 2001. Influência de fungos micorrízicos arbusculares sobre o crescimento de dois genótipos de aceroleira (Malpighia emarginata O. C.). Pesquisa Agropecuária Brasileira 36: 893-901.

Domatto Junior, E.R.; Villas Bôas, R.L. \& Leonel, S. 2007. Influência da adubação com composto orgânico no crescimento, desenvolvimento e produção da bananeira 'prata-anã' (Musa AAB). Revista Energia na Agricultura 22: 27-37.

Douds, D.D.; Nagahashi, G.; Pfeffer, P.E.; Reider, C. \& Kayser, W.M. 2006 On-farm production of AM fungus inoculum in mixtures of compost and vermiculite. Bioresource Technology 97: 809-818.

França, S.C.; Gomes-da-Costa, S.M. \& Silveira, A.P.D. 2007. Microbial activity and arbuscular mycorryzal fungal diversity in convencional and organic citrus orchards. Biological Agriculture and Horticulture 25: 91-102. 
Genre, A. \& Bonfante, P. 2010. The marking of symbiotic cells in arbuscular mycorrhizal roots. In: Koltai, H. \& Kapulnik, Y. Arbuscular mycorrhizas: physiology and function. New York, Springer.

Gerdemann, J. W. \& Nicolson T. H. 1963. Spores of mycorrhizal Endogone species extracted from soil by wet sieving and decanting. Transactions of the British Mycological Society 46: 235-244.

Giovannetti, M. \& Mosse, B. 1980. An evaluation of techniques for measuring vesicular arbuscular mycorrhizal infection in roots. New Phytologist 84: 489-500.

Gryndler, M.; Jansa, J.; Hrselová, H.; Chvátalová, I. \& Vosátka, M. 2003. Chitin stimulates development and sporulation of arbuscular mycorrhizal fungi. Applied Soil Ecology 22: 283-287.

Gryndler, M.; Sudová, R.; Püschel, D. Rydlová, J.; Janousková, M. \& Vosátka, M. 2008. Cultivation of high-biomass crops on coal mine spoil Banks: Can microbial inoculation compensate for high doses of organic matter? Bioresource Technology 99: 6391-6399.

Hodge, A. 2004. The plastic plant: root responses to Heterogeneous supplies of nutrients. New Phytologist 162: 9-24.

Ilbas, A. I. \& Sahin, S. 2005. Glomus fasciculatum inoculation improves soybean production. Acta Agriculture Scandinavica Section B-Soil and Plant Sciences 12: 1-6.

Jenkins, W. R. 1964. A rapid centrifugal-flotation technique for separating nematodes from soil. Plant Risease Reporter 48: 692

Martín, T.; Sampedro, I.; García-Romera, I.; García-Garrido, J. M. \& Ocampo, J. A. 2002. Arbuscular mycorrhizal colonization and growth of soybean (Glycine max) and lettuce (Lactuca sativa) and phytotoxic effect of olive mill residues. Soil Biology and Biochemistry 34: $1769-1775$.

Moreira, F. M. S. \& Siqueira, J. O. 2002. Micorrizas. In:Microbiologia e bioquímica do solo. Lavras, UFLA.

Pouyu-Rojas, E.; Siqueira, J. O. \& Santos, J. G. D. 2006. Compatibilidade simbiótica de fungos micorrízicos arbusculares com espécies arbóreas tropicais. Revista Brasileira de Ciência do Solo 30: 413-424.

Schiavo, J. A. \& Martins, M. A. 2002. Produção de mudas de goiabeira (Psidium guajava L.), inoculadas com o fungo micorrízico arbuscular Glomus clarum, em substrato agro-industrial. Revista Brasileira Fruticultura 24: 519-523.

Silva, D.K.A.; Silva, F.S.B.; Yano-Melo, A.M. \& Maia, L.C. 2008. Uso de vermicomposto favorece o crescimento de mudas de gravioleira (Annona muricata L. 'Muricata') associada a fungos micorrízicos arbusculares. Acta Botanica Brasilica 22: 863-869.
Silva, M.A.; Cavalcante, U.M.T.; Silva, F.S.B.; Soares, S.A.G. \& Maia, L.C. 2004. Crescimento de mudas de maracujazeiro-doce (Passiflora alata curtis) associados a fungos micorrízicos arbusculares (Glomeromycota). Acta Botanica Brasilica 18: 981-985.

Silva, M.A.; Silva, F.S.B.; Yano-Melo, A.M.; Melo, N.F. \& Maia, L.C. 2006. Fungos micorrízicos arbusculares e vermicomposto na aclimatação de Alpinia purpurata (Viell.) Schum e Zinziber spectabile Griff. (Zingiberaceae). Acta Botanica Brasilica 20: 249-256.

Silveira, A.P.D. 1998. Ecologia de fungos micorrízicos arbusculares. In: Melo, I.S. \& Azevedo, J.L. (Eds.). Ecologia microbiana. Jaguariúna, Embrapa - CNPMA

Silveira, A.P.D. \& Gomes, V.F.F. 2007. Micorrizas Arbusculares em Plantas Frutíferas Tropicais. In: Silveira, A. P. D. \& Freitas, S. S. (Eds.). Microbiota do solo e qualidade ambiental. Instituto Agronômico, Campinas.

Silveira, S.V.; Souza, P.V.O. \& Koller, O.C. 2002. Efeito de fungos micorrízicos arbusculares no desenvolvimento do abacateiro. Pesquisa Agropecuária Brasileira 37: 1597-1604.

Soares, A.C.F.; Silva, R.P. \& LIMA, G.S. 2003. Mudas de maracujazeiro amarelo inoculadas com fungos micorrízicos em diferentes substratos. Magistra 15(2): 265-268.

Souza, C.A.S.; Corrêa, F.L.O.; Mendonça, V.L. \& Carvalho, J.G. 2003. Crescimento de mudas de gravioleira (Annona muricata L.) em substrato com superfosfato simples e vermicomposto. Revista Brasileira de Fruticultura 25: 453-456.

Statsoft. 2002. Statistica for Windows. Tulsa, USA.

Trindade, A.V.; Lins, G.M.L. \& Maia, I. C. S. 2003. Substratos e fungo micorízico arbuscular em mudas micropropagadas de bananeira na fase de aclimatização. Revista Brasileira de Fruticultura 25: 37-42.

Trindade, A.V.; Siqueira, J.O. \& Almeida, F.P. 2001. Dependência micorrízica de variedades comerciais de mamoeiro. Pesquisa Agropecuária Brasileira 36: 1485-1494.

Vaidya, G.S.; Shrestha, K.; Khadge, B.R.; Khadge, N.C. \& Wallander, H. 2007. Study of biodiversity of arbuscular mycorrhizal fungi in addition with different organic matter in different seasons of kavre district (Central Nepal). Scientific World 5: 75-80.

Vandresen, J.; Nishidate, F.R.; Torezan, J.M.D. \& Zangaro, W. 2007. Inoculação de fungos micorrízicos arbusculares e adubação na formação e pós transplante de mudas de cinco espécies arbóreas nativas do sul do Brasil. Acta Botanica Brasilica 21:753-765.

Yano-Melo, A.M.; Saggin Júnior, J.; Lima-Filho, J.M.; Melo, N.F. \& Maia, L.C. 1999. Effect of arbuscular mycorrhizal fungi on the acclimatization of micropropagated banana plantlets. Mycorrhiza 9: 119-123. 